\begin{tabular}{lcccccc}
\hline \multicolumn{5}{c}{ Table 1 } & Pathological analysis of GFP transgenic mice & \\
\hline & Non-transgenic & A & B & C & D \\
Number & 9 & 4 & 4 & 6 & 8 \\
$\begin{array}{l}\text { Body } \\
\text { weight (g) }\end{array}$ & $20.96 \pm 1.14$ & $21.30 \pm 2.02$ & $20.97 \pm 0.82$ & $21.03 \pm 0.86$ & $21.17 \pm 1.10$ \\
$\begin{array}{l}\text { Heart } \\
\text { weight (mg) }\end{array}$ & $85.4 \pm 6.5$ & $90.6 \pm 11.0$ & $90.6 \pm 10.8$ & $131.4 \pm 18.2^{*}$ & $144.1 \pm 26.2^{*}$ \\
$\begin{array}{l}\text { Tibia } \\
\text { length (mm) }\end{array}$ & $16.1 \pm 0.1$ & $16.1 \pm 0.2$ & $16.0 \pm 0.1$ & $16.2 \pm 0.1$ & $16.0 \pm 0.2$ \\
HW/BW (mg/g) & $4.1 \pm 0.3$ & $4.3 \pm 0.3$ & $4.3 \pm 0.5$ & $6.2 \pm 0.7^{*}$ & $6.9 \pm 1.5^{*}$ \\
HW/TL (mg/mm) & $5.3 \pm 0.4$ & $5.6 \pm 0.6$ & $5.7 \pm 0.7$ & $8.1 \pm 1.2^{*}$ & $9.0 \pm 1.8^{*}$ \\
\hline
\end{tabular}

Whole hearts were excised from non-transgenic (NTG) and transgenic (A, B, C and D) mice 8 weeks of age, and were weighed (HW) and normalized to body weight (BW) or tibia length (TL). Top row, number of mice in each group. Data represent mean \pm s.d. ${ }^{*}, P<0.005$, compared with non-transgenic.

ments should include additional controls, allowing differentiation between specific and nonspecific effects of expression of the transgene.

\author{
WeEI-YuARn HuAnG ${ }^{1}$, \\ Jose Aramburu², \\ PAMEla S. DOUGLAS ${ }^{1} \&$ \\ SEIGO IZUMO ${ }^{1}$
}

${ }^{\prime}$ Cardiovascular division, Beth Israel Deaconess Medical Center, Harvard Medical School, Boston, Massachusetts 02215, USA ${ }^{2}$ The Center for Blood Research, 200 Longwood Avenue, Boston, Massachusetts 02215, USA Correspondence should be addressed to S.I.; email: sizumo@caregroup.harvard.edu

1. James, J.F., Hewett T.E. \& Robbins, J. Cardiac physiology in transgenic mice. Circ. Res. 82, 407-415 (1998).

2. Kadambi, V. I. \& Kranias, E. G. Genetically engineered mice: model systems for left ventricular failure. J. Card. Fail. 4, 349-361 (1998).

3. Heim, R. Prasher, D.C. \& Tsien, R.Y. Wavelength mutations and posttranslational autoxidation of green fluorescence protein. Proc. Natl. Acad. Sci. USA 91, 12501-12504 (1994).

4. Godwin,A.R. et al. Detection of targeted GFPHox gene fusions during mouse embryogenesis. Proc. Natl. Acad. Sci. USA 95, 13042-13047 (1998).

5. Subramaniam, A. et al. Tissue-specific regulation of the alpha-myosin heavy chain gene promoter in transgenic mice. J. Biol. Chem. 266, 24613-24620 (1991).

6. Okabe, M. et al. Green mice as a source of ubiquitous green cells. FEBS Lett. 407, 313-319 (1997).

\title{
Human neural progenitor cells: better blue than green?
}

To the Editor- We read with great interest the exciting results of Roy et al. ${ }^{1}$ in the March issue of Nature Medicine, reporting the purification of progenitor cells from heterogeneous cultures derived from the adult human hippocampus, after expression of enhanced green fluorescent protein (EGFP) from the tubulin $\alpha 1$ or nestin promoter-enhancer. These progenitors have the ability to differentiate into mature neurons. We were concerned about two aspects not discussed in detailed: To what extent does EGFP induce differentiation by itself, and what is the remaining mitotic activity of these cells?

It was reported that $61 \%$ of the sorted nestin:EGFP cells differentiated into $\beta$ tubulin-III positive cells, whereas only $25 \%$ did so in unsorted parallel samples (we assume these cells were also transfected). This may reflect a relative purification or enrichment, but also may be indicative of a direct effect of EGFP in inducing neuronal differentiation. BrdU incorporation data indicated that only a minor fraction $(22 \%)$ of the sorted cells that developed into $\beta$-tubulin III cells did divide in the week after sorting. It was reported that clonal derivatives of these cells exist, although experiments aimed at determining if the fluorescent cells could divide further, and if they continued generating neurons, were not presented.
Our own work with human neural stem cells (HNSCs) derived from telencephalon and diencephalon and either genetically perpetuated with V-MYC (ref. 2; HNSC.100 cells) or epigenetically expanded with growth factors (epidermal growth factor and fibroblast growth factor 2) indicates that it is not possible to derive stable sublines expressing EGFP for more than a month. We believe there is a definite interference (toxicity, induction of differentiation, or both) of EGFP with the normal biological properties of HNSCs. In the cell cultures described above, transgene expression is acceptable at both 48 hours and 10 days after lipofection or electroporation (for example, $3 \%$ and $1.5 \%$ of lipofected cells are positive for GFP expression at these times), but these cells can not be expanded to generate stable sublines expressing the transgene. During the 3-4 weeks after transfection, most cells remain as single fluorescent cells without dividing, and adopt a very differentiated morphology resembling neurons. These events occur regardless of the application of drug selection to the cultures, and consistently result in the loss of the fluorescent cells upon passaging and continued expansion. In contrast, sublines expressing LacZ or other therapeutic genes can be easily generated, isolated and established using the same type of constructs equipped with viral or cellular promoters. Also, the generation of stable sublines of HNSCs expressing LacZ from a retroviral vector has been reported ${ }^{3}$.

From the report by Roy et al. ${ }^{1}$, it is possible to infer that the fluorescent and purified cells can be expanded further to generate a therapeutic cell source for clinical use "to re-populate the damaged or degenerated adult human hippocampus. ${ }^{11}$ It would be useful to learn if there is evidence supporting the view that the purified cells expressing EGFP can be expanded beyond one week and if they still can differentiate into neurons. It would also be of interest to know if the marker transgene is stably expressed.

Alberto Martínez-Serrano, Ana Villa, Beatriz Navarro, F. Javier Rubio and Carlos Bueno Center of Molecular Biology Severo Ochoa. Autonomous University of Madrid. 28049Madrid, Spain. Correspondence should be address to A.M.S.; email: amserrano@cbm.uam.es

Goldman and Roy reply-We thank Martinez-Serrano et al. for their comments. They raise several interesting issues: Can expression of GFP influence phenotypic differentiation or maturation? Do GFP-sorted progenitor cells remain mitotically competent? Can stable lines of GFP-expressing cells be derived? 